\title{
Immunologic cellular characteristics of the tumour microenvironment of hepatocellular carcinoma drive patient outcomes
}

\author{
Georgi Atanasov ${ }^{1,2,3^{*}}$ (D), Karoline Dino ${ }^{1}$, Katrin Schierle ${ }^{4}$, Corinna Dietel ${ }^{1}$, Gabriela Aust ${ }^{5}$, Johann Pratschke², \\ Daniel Seehofer ${ }^{1}$, Moritz Schmelzle ${ }^{1,2}$ and Hans-Michael Hau ${ }^{1}$
}

\begin{abstract}
Background: Anti-tumour immune competence has an impact in hepatocarcinogenesis and success of anti-cancer therapies. Tumour-infiltrating lymphocytes (TILs) and monocytes/macrophages (TAMs) are proposed to have significance in cancer. However, there is only limited data concerning their impact on patient outcome and survival in hepatocellular carcinoma (HCC).

Methods: Frequencies of $\mathrm{CD}_{68}{ }^{+}, \mathrm{CD} 163^{+} \mathrm{M2}$-polarized TAMs and TILs were measured in de novo HCC tumours in noncirrhosis $(n=58)$ using immunohistology and correlated to patients' clinicopathological characteristics and survival rates.

Results: Patients with tumours marked by appearance of TILs and CD68 ${ }^{+}$TAMs showed an improved 1-, 3- and 5-year recurrence-free survival (all $p \leq 0.05$ ). CD68 ${ }^{+}$TAMs were associated with reduced incidence of recurrent and multifocal disease. Conversely, CD163 ${ }^{+}$TAMs were associated with multifocal HCC and lymphangiosis carcinomatosa (all $p \leq 0.05$ ).

Conclusions: TILS and CD68 ${ }^{+}$TAMs are associated with multiple tumour characteristics and patient survival in HCC. However, there is only scarce data about the biology underlying their mechanistic involvement in human tumour progression. Thus, experimental data on functional links might help develop novel immunologic checkpoint inhibitor targets for liver cancer.
\end{abstract}

Keywords: Hepatocellular carcinoma, Monocytes/macrophages, Tumour-infiltrating lymphocytes, M2 macrophages, Biomarkers, Prognosis

\section{Background}

Tumour-related mechanisms define the host immune functions in the tumour microenvironment and decrease the efficiency of the anti-tumour immune competence. This phenomenon plays a key role in the process of hepatocarcinogenesis, where tumour infiltration with immune competent cells exerts a strong influence on prognosis [1]. In liver cancer, tumour-associated

\footnotetext{
* Correspondence: georgi.atanasov@charite.de

'Department of Visceral-, Transplantation-, Thoracic- and Vascular Surgery, University Hospital Leipzig, Leipzig, Germany

2Department of Surgery, Campus Charité Mitte Campus Virchow Klinikum, Charité - Universitätsmedizin Berlin, corporate member of Freie Universität Berlin, Humboldt-Universität zu Berlin, and Berlin Institute of Health, Berlin, Germany

Full list of author information is available at the end of the article
}

macrophages (TAMs) and monocyte subsets with distinguished functional polarization have a significant impact on cancer-related inflammation and foster tumour escape mechanisms and progression [2]. These subpopulations of immunologic phenotypes are related to as classically (M1) or alternatively activated (M2) monocytes/macrophages. These monocytes/macrophages deploy their immunoregulatory activities in close interplay with $\mathrm{T}$ cell-dependent responses [2].

Tumour-infiltrating lymphocytes (TILs) play a major role in the progression of solid malignancies and can have a strong influence on the success of the related anti-cancer therapies. TILs in hepatocellular carcinoma (HCC) are mainly T cells. TILs are the hallmark of the anti-cancer immunity in human cancer, on grounds of

(C) The Author(s). 2019 Open Access This article is distributed under the terms of the Creative Commons Attribution 4.0 International License (http://creativecommons.org/licenses/by/4.0/), which permits unrestricted use, distribution, and 
their ability to specifically interact with and neutralize tumour-related neoantigens [3]. TILs' immune activity may influence hepatocarcinogenesis not only by direct effects on the adaptive immune system and cytokine interactions, but also further by modulating neoangiogenesis and innate immune responses, i.e. related monocyte/macrophages functions [4-8]. Therefore, the quantification of TILs in solid tumours might help to deliver novel insights concerning their role in the process of hepatocarcinogenesis and to monitor the therapy outcome with immunologic checkpoint inhibition.

Major progress in the efficacy of adjuvant therapies for hepatic malignancies has emerged. However, the restraints of these neoadjuvant regimens constitute an important clinical problem [9]. Therefore, an additional immune checkpoint blockade represents an attractive therapeutic concept that complements these current therapies in cancer. Furthermore, the pre- and on-treatment quantification of the immunologic infiltrates could deliver novel biomarkers for state of the art disease management, based on the fact that immunological checkpoint targeting is effective only in a scarce amount of the tumour patients [10]. HCC can arise de novo in non-cirrhotic hepatic environment in approximately $20 \%$ of all cases [11]. However, this subgroup of patients usually presents at an advanced stage of hepatocarcinogenesis, due to the lack of symptoms and surveillance. Therefore, our study aimed to assess the presence and abundance of tumour-infiltrating subsets of monocytes/macrophages and TILs in advanced de novo HCC in non-cirrhosis. This study investigated also their association with tumour recurrence, patient survival and outcome.

\section{Methods}

\section{Patients and tumour specimens}

Our retrospective study was conducted in 58 patients with de novo HCC in non-cirrhosis. In all patients, a major liver resection with curative intent was performed. None of the included patients had history of viral hepatitis or were treated with neoadjuvant radio- and/or chemotherapy before the tumour resection. Formalin-fixed and paraffinembedded surgical specimens, embedding a representative tumour sample for immunohistochemical staining, were obtained from the archives of the Department of Pathology. The study was conducted in accordance with the ethical guidelines of the Declaration of Helsinki and was approved by the Ethics Committee of the Leipzig University.

\section{Immunohistology}

The protocols for immunohistology and quantification of positive staining have been published previously [1216]. The abundance of infiltrating TILs, $\mathrm{CD}^{+} 8^{+}$and $\mathrm{CD}_{163}{ }^{+}$TAMs were measured in regard to the tumour central area (TCA) and the tumour-infiltrating front (TIF). Zeiss Axio Imager A1 Phase Contrast microscope (Carl Zeiss, Jena, Germany) was used to asses positive staining. Table 1 summarizes the antibodies and reagents used to conduct immunohistology.

\section{Density quantification of cellular infiltrates}

Quantification was performed as described [13]. In brief, tumour-infiltrating immune cells were categorized as negative/absent in up to $5 \%$ positive cells $(0-5 \%$ positive cells, score 0 ) and positive/present (> 5\% positive cells, score 1 ). HCC patients were then assigned to two groups either to be negative or positive for $\mathrm{CD}^{+} 8^{+}$or $\mathrm{CD}_{163}{ }^{+}$TAMs. Evaluation of TILs was performed using routine H\&E slides as described [17]. Briefly, the extent of lymphocyte abundance in the tumour area was categorized as none (score 0), low (score 1), moderate (score 2) or high (score 3). Accordingly, $\mathrm{HCC}$ patients were then assigned to the $\mathrm{TIL}^{-}$(none to low infiltration) or $\mathrm{TIL}^{+}$group (moderate to high infiltration).

\section{Statistical analysis}

The IBM SPSS statistics software was used to perform survival and univariate analysis and to produce the Kaplan-Meier curves (Version 25/Year 2017/USA). The log-rank test was applied to compare differences in survival distributions. The Cox proportional hazards model was utilized to conduct multivariate analysis for the significant parameters in the univariate analysis. The chi-square test, Fisher's exact test or Student's $t$ test (independent sample) were applied to compare categorical and continuous variables. Statistical differences were considered significant for $p \leq 0.05$.

\section{Results}

Table 2 summarizes the clinicopathological characteristics of all patients included in the current work. The studied population of HCC patients had 1-, 3- and 5year survival of $76.4 \%, 64.1 \%$ and $62.2 \%$, respectively. The recurrence-free survival rates 1-, 3- and 5- year after tumour resection were $63.5 \%, 57.7 \%$ and $53.6 \%$, respectively. In 23/58 (39.7\%) patients, a recurrent tumour disease was detected and 17/58 (29.3\%) patients

Table 1 Antibodies and reagents used for immunostaining

\begin{tabular}{lllllllll}
\hline Antigen & $\mathrm{m} / \mathrm{p}$ & Clone & Species & Company & Secondary antibody & Company & Substrate & Antigen retrieval \\
\hline CD68 & $\mathrm{m}$ & PG-M1 & Mouse & Agilent & anti-mouse-lg/ peroxidase & Vector & DAB & Tris/EDTA pH 9.0 \\
CD163 & $m$ & 10D6 & Mouse & $\begin{array}{l}\text { Leica Biosystems, Newcastle } \\
\text { Upon Tyne, UK }\end{array}$ & anti-mouse-lg/ peroxidase & Vector & DAB & $10 \mathrm{mM} \mathrm{citrate,} \mathrm{pH} \mathrm{5.5}$ \\
& & & & & &
\end{tabular}


Table 2 Clinicopathological characteristics of the patients included in the study

\begin{tabular}{|c|c|}
\hline Variable & Value (\%) \\
\hline No. of patients & 58 \\
\hline \multicolumn{2}{|l|}{ Gender } \\
\hline Female & $13(22.4 \%)$ \\
\hline Male & $45(77.6 \%)$ \\
\hline \multicolumn{2}{|l|}{ Patient age (years) } \\
\hline$\leq 60$ & $21(36.2 \%)$ \\
\hline$>60$ & $37(63.8 \%)$ \\
\hline \multicolumn{2}{|l|}{ Pathologic T stage } \\
\hline $\mathrm{T} 1 / \mathrm{T} 2$ & $29(50.0 \%)$ \\
\hline $\mathrm{T} 3 / \mathrm{T} 4$ & $29(50.0 \%)$ \\
\hline \multicolumn{2}{|l|}{ Pathologic N stage } \\
\hline Positive & $11(19.0 \%)$ \\
\hline Negative & $47(81.0 \%)$ \\
\hline \multicolumn{2}{|c|}{ Lymphangiosis carcinomatosa } \\
\hline Positive & $17(29.3 \%)$ \\
\hline Negative & $41(70.7 \%)$ \\
\hline \multicolumn{2}{|l|}{ Angioinvasion } \\
\hline Positive & $30(51.7 \%)$ \\
\hline Negative & $28(48.3 \%)$ \\
\hline \multicolumn{2}{|c|}{ Multiple tumour nodules } \\
\hline With & $13(22.4 \%)$ \\
\hline Without & $45(77.6 \%)$ \\
\hline \multicolumn{2}{|l|}{ Tumor size (mm) } \\
\hline$\leq 50$ & $11(19.0 \%)$ \\
\hline$>50$ & $47(81.0 \%)$ \\
\hline \multicolumn{2}{|c|}{ Pathologic R category } \\
\hline RO & $49(84.5 \%)$ \\
\hline $\mathrm{R} 1 / \mathrm{R} 2$ & $9(15.5 \%)$ \\
\hline \multicolumn{2}{|c|}{ Histologic differentiation } \\
\hline Well & $11(19.0 \%)$ \\
\hline Moderate/poor & $47(81.0 \%)$ \\
\hline \multicolumn{2}{|l|}{ Distant metastases } \\
\hline With & $11(19.0 \%)$ \\
\hline Without & $47(81.0 \%)$ \\
\hline \multicolumn{2}{|l|}{ Tumor recurrence } \\
\hline With & $23(39.7 \%)$ \\
\hline Without & $35(60.3 \%)$ \\
\hline \multicolumn{2}{|l|}{ Local recurrence } \\
\hline With & $17(29.3 \%)$ \\
\hline Without & $41(70.7 \%)$ \\
\hline
\end{tabular}

developed a local tumour recurrence. A metastatic disease was seen in 11/58 (19.0\%) patients.

\section{Distribution of monocytes/macrophages and tumour-} infiltrating lymphocytes in HCC

Figure 1 provides characteristic images for the abundance of TILs and $\mathrm{CD}^{+} 8^{+}$or $\mathrm{CD} 163^{+}$TAMs in HCC. Tables 2, 3,4 and 5 summarize the respective statistical data of the patients. TILs and $\mathrm{CD} 68^{+}$or $\mathrm{CD} 163^{+}$TAMs revealed a homogeneous expression pattern in TCA and TIF and were also detected in areas of HCC necrosis (Fig. 1a-f).

\section{Monocytes/macrophages are associated with reduced} incidence of tumour recurrence and formation of multiple tumour nodules in HCC patients

CD68 ${ }^{+}$TAMs in TIF were associated with reduced occurrence of recurrent HCC. In the CD68 ${ }^{+}$group, only 19/53 (35.8\%) patients suffered overall tumour recurrence, whereas in the $\mathrm{CD}^{-} 8^{-}$group, $4 / 5(80.0 \%)$ patients had recurrent disease $(p=0.05$; Table 3$)$. $\mathrm{CD}^{+} 8^{+}$TAMs in TIF were also correlated with reduced formation of multiple tumour nodules $(p=0.035)$. In the $\mathrm{CD}^{+} 8^{+}$group, only $10 /$ $53(18.9 \%)$ patients showed this feature, whereas in the CD68 ${ }^{-}$group, these were $2 / 5(40.0 \%)$ patients $(p=0.035)$.

\section{M2-polarized macrophages are associated with} lymphangiosis carcinomatosa and formation of multiple tumour nodules in HCC patients

$\mathrm{CD}_{163}{ }^{+}$TAMs in TCA were associated with the formation of multiple tumour nodules $(p=0.016$; Table 4$)$. In the $\mathrm{CD}_{163^{+}}$group, $36 / 42(85.7 \%)$ patients had multiple tumour nodules; in the CD163- group in 9/16 (56.3\%) patients, this was diagnosed $(p=0.016)$. Moreover, when considering the TIF, in the CD163- group, 31/39 (79.5\%) patients had absence of lymphangiosis carcinomatosa. In the $\mathrm{CD}_{163}{ }^{+}$group, these were $10 / 19$ (52.6\%) patients $(p=0.035)$. No significant association between $\mathrm{CD} 163^{+}$ TAMs in TCA or TIF with $\mathrm{CD}^{+} 8^{+}$TAMs could be detected.

\section{Tumour-infiltrating lymphocytes are associated with} intratumoural monocytes/macrophages in HCC patients TILs in TCA or TIF were not correlated with clinicopathological features of HCC patients (Table 5). However, in regard to the TCA, TILs and $\mathrm{CD}^{+} 8^{+}$TAMs revealed a strong correlation. In the $\mathrm{TIL}^{+}$group in 20/20 (100\%) and in the $\mathrm{TIL}^{-}$group in only $11 / 38(28.9 \%)$ patients, high frequencies of $\mathrm{CD} 68^{+}$TAMs were detected $(p=0.008)$. No significant correlations between TILs in TCA or TIF with CD163 $3^{+}$TAMs could be observed. 


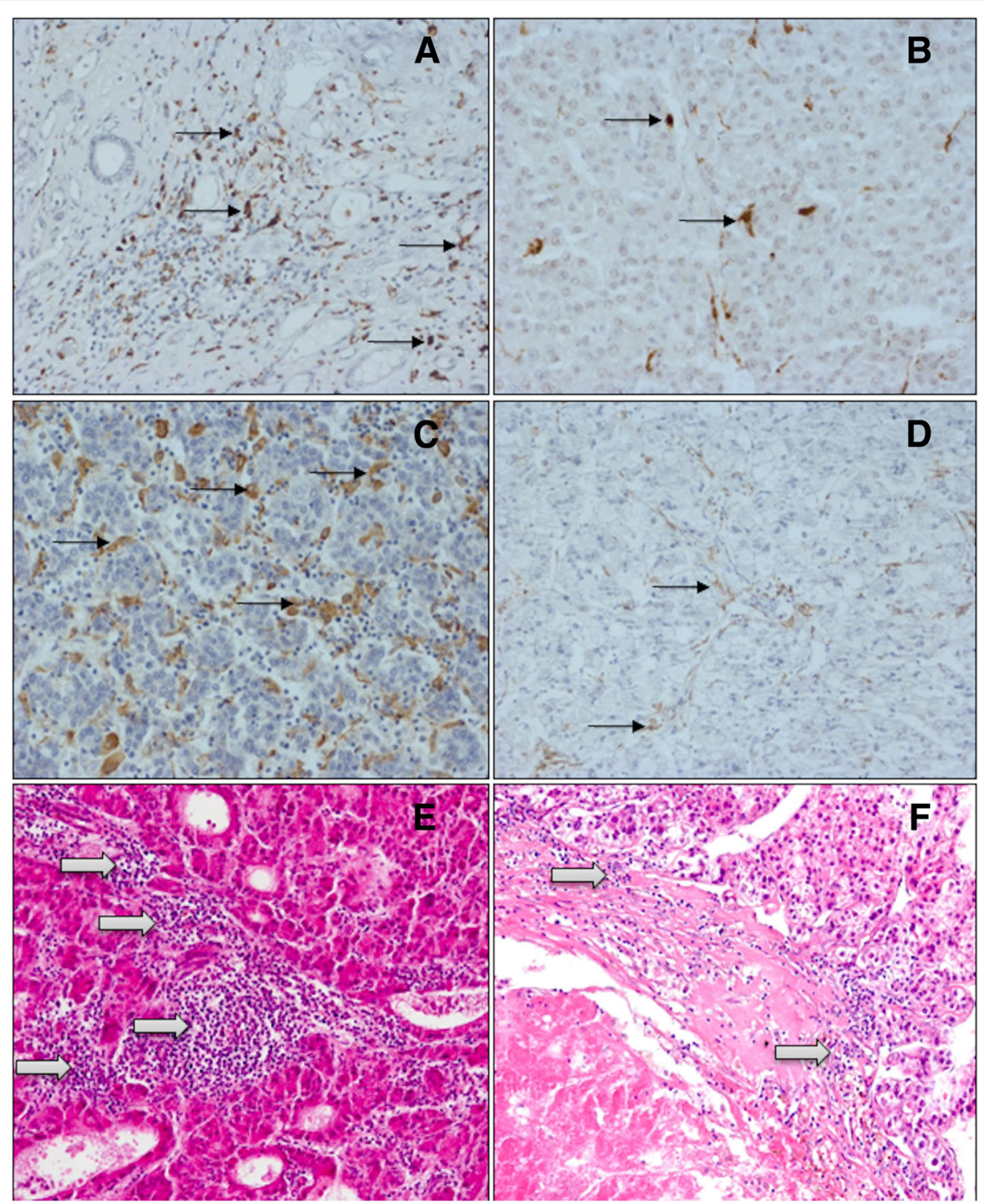

Fig. $1 \mathrm{Imm}$ unohistology of monocytes/macrophages and H\&E staining of TILs in tumour central area (TCA) of HCC specimens. a High density of CD68 ${ }^{+}$TAMs. $\mathbf{b}$ Low density of CD68 ${ }^{+}$TAMs. $\mathbf{c}$ High density of $C D 163^{+}$TAMs. $\mathbf{d}$ Low density of CD163+ TAMs. e High density of TILs. $\mathbf{f}$ Low density of TILs. Legend: left column, high density; right column, low density. Black arrows indicate monocytes/macrophages, white arrows TILs

\section{Influence of monocytes/macrophages and tumour-} infiltrating lymphocytes on survival in HCC patients In our study, $\mathrm{CD}^{+} 8^{+}$TAMs and TILs were associated with patients' recurrence-free survival. Figure 2 shows the Kaplan-Meier survival curves. Tables 2, 3, 4 and 5 show the statistical evaluation of all patients. Recurrence-free survival rates were significantly improved in patients with TILs in TCA (Fig. 2a). One, 3 and 5 years after surgery, these were $68.9 \%, 63.9 \%$ and $61.6 \%$, respectively. Conversely, the survival was $37.8 \%, 23.4 \%$ and $23.4 \%$ at 1,3 and 5 years postsurgery, respectively, in patients without TILs in TCA ( $p=$ 0.05). Similar data was obtained in regard to $\mathrm{CD} 68^{+}$TAMs in TIF (Fig. 2b). The recurrence-free survival rates were $66.9 \%, 63.3 \%$ and $60.0 \%$ at 1,3 and 5 years for patients with
CD68 ${ }^{+}$TAMs in TIF. Contrarily, the recurrence-free survival was $28.7 \%$ at 1 year post-surgery in HCC patients without these cells in the TIF. Of note, survival beyond 3 years after surgery could not be reached in patients without CD68 ${ }^{+}$TAMs in TIF $(p=0.04)$. CD163 ${ }^{+}$TAMs in TCA or TIF did not reveal any significant correlation with overall or recurrence-free survival of the HCC patients $\left(\mathrm{CD} 163^{+}\right.$ TAMs in TCA: overall survival $p=0.858$, recurrence-free survival $p=0.283$; $\mathrm{CD}_{163^{+}}$TAMs in TIF: overall survival $p=0.410$, recurrence-free survival $p=0.405$ ).

\section{Discussion}

In the present work, we determined the level of abundance of monocytes/macrophages and TILs in tumour 
Table 3 Correlation of $\mathrm{CD} 8^{+}$TAMs at the tumour-infiltrating front (TIF) with clinicopathological characteristics in HCC

\begin{tabular}{|c|c|c|c|}
\hline Variable & $\mathrm{CD}^{2} 8^{+} / \mathrm{TIF}$ & $\mathrm{CD}^{2} 8^{-} / \mathrm{TIF}$ & $p$ value \\
\hline No. of patients & 53 & 5 & \\
\hline Patient age, years & & & 0.324 \\
\hline$\leq 60$ & $33(62.3 \%)$ & $4(80.0 \%)$ & \\
\hline$>60$ & $20(37.7 \%)$ & $1(20.0 \%)$ & \\
\hline Gender & & & 0.430 \\
\hline Female & $42(79.2 \%)$ & $3(60.0 \%)$ & \\
\hline Male & $11(20.8 \%)$ & $2(40.0 \%)$ & \\
\hline Local tumour recurrence & & & 0.583 \\
\hline Positive & $15(28.3 \%)$ & $2(40.0 \%)$ & \\
\hline Negative & $38(71.7 \%)$ & $3(60.0 \%)$ & \\
\hline Overall tumour recurrence & & & 0.050 \\
\hline Positive & $19(35.8 \%)$ & $4(80.0 \%)$ & \\
\hline Negative & $34(64.2 \%)$ & $1(20.0 \%)$ & \\
\hline Distant Metastases & & & 0.209 \\
\hline Positive & $9(17.0 \%)$ & $2(40.0 \%)$ & \\
\hline Negative & $44(83.0 \%)$ & $3(60.0 \%)$ & \\
\hline Multiple tumour nodules & & & 0.035 \\
\hline Positive & $10(18.9 \%)$ & $2(40.0 \%)$ & \\
\hline Negative & $43(81.1 \%)$ & $3(60.0 \%)$ & \\
\hline Tumour size (mm) & & & 0.951 \\
\hline$\leq 50$ & $10(10.0 \%)$ & $1(20.0 \%)$ & \\
\hline$>50$ & $43(90.0 \%)$ & $4(80.0 \%)$ & \\
\hline R status & & & 0.772 \\
\hline Positive & $8(15.1 \%)$ & $1(20.0 \%)$ & \\
\hline Negative & 45 (84.9\%) & $4(80.0 \%)$ & \\
\hline Angioinvasion & & & 0.583 \\
\hline Positive & $25(47.2 \%)$ & $2(40.0 \%)$ & \\
\hline Negative & $28(52.8 \%)$ & $3(60.0 \%)$ & \\
\hline Lymphangiosis carcinomatosa & & & 0.583 \\
\hline Positive & $15(28.3 \%)$ & $2(40.0 \%)$ & \\
\hline Negative & $38(71.8 \%)$ & $3(60.0 \%)$ & \\
\hline Histologic differentiation & & & 0.951 \\
\hline Well & $10(10.0 \%)$ & & $1(20.0 \%)$ \\
\hline Moderate/poor & $43(90.0 \%)$ & & $4(80.0 \%)$ \\
\hline Pathologic T stage & & & 0.148 \\
\hline $\mathrm{T} 1 / \mathrm{T} 2$ & $28(53.8 \%)$ & $1(20.0 \%)$ & \\
\hline $\mathrm{T} 3 / \mathrm{T} 4$ & $24(46.2 \%)$ & $4(80.0 \%)$ & \\
\hline Pathologic N stage & & & 0.658 \\
\hline Positive & $2(03.8 \%)$ & $0(00.0 \%)$ & \\
\hline Negative & 51 (96.2\%) & 5 (100.0\%) & \\
\hline
\end{tabular}

Table 4 Correlation CD163+ TAMs in the tumour central area (TCA) or tumour-infiltrating front (TIF) with clinicopathological characteristics in HCC

\begin{tabular}{|c|c|c|c|}
\hline Variable & $\mathrm{CD}_{163^{+}} / \mathrm{TCA}$ & $\mathrm{CD}_{163^{-}} / \mathrm{TCA}$ & $p$ value \\
\hline No. of patients & 42 & 16 & \\
\hline Patient age, years & & & 0.177 \\
\hline$\leq 60$ & $13(31.0 \%)$ & $8(50.0 \%)$ & \\
\hline$>60$ & $29(69.9 \%)$ & $8(50.0 \%)$ & \\
\hline Gender & & & 0.680 \\
\hline Female & $10(76.2 \%)$ & $3(18.8 \%)$ & \\
\hline Male & $32(23.8 \%)$ & $13(81.2 \%)$ & \\
\hline Local tumour recurrence & & & 0.398 \\
\hline Positive & $11(26.2 \%)$ & $6(37.5 \%)$ & \\
\hline Negative & $31(73.8 \%)$ & $10(62.5 \%)$ & \\
\hline Overall tumour recurrence & & & 0.320 \\
\hline Positive & $15(35.7 \%)$ & $8(50.0 \%)$ & \\
\hline Negative & $27(64.3 \%)$ & $8(50.0 \%)$ & \\
\hline Distant metastases & & & 0.469 \\
\hline Positive & $7(16.7 \%)$ & $4(25.0 \%)$ & \\
\hline Negative & $35(83.3 \%)$ & $12(75.0 \%)$ & \\
\hline Multiple tumour nodules & & & 0.016 \\
\hline Positive & $36(85.7 \%)$ & $9(56.3 \%)$ & \\
\hline Negative & $6 \quad(14.3 \%)$ & $7(43.8 \%)$ & \\
\hline Tumour size (mm) & & & 0.438 \\
\hline$\leq 50$ & $9(21.4 \%)$ & $2(12.5 \%)$ & \\
\hline$>50$ & $33(78.6 \%)$ & $14(87.5 \%)$ & \\
\hline R status & & & 0.695 \\
\hline Positive & $35(15.1 \%)$ & $2(12.5 \%)$ & \\
\hline Negative & $7(84.9 \%)$ & $14(87.5 \%)$ & \\
\hline Angioinvasion & & & 0.311 \\
\hline Positive & $20(47.6 \%)$ & $10(62.5 \%)$ & \\
\hline Negative & $22(52.4 \%)$ & $6(37.5 \%)$ & \\
\hline Lymphangiosis carcinomatosa & & & 0.656 \\
\hline Positive & $13(31.0 \%)$ & $4(25.0 \%)$ & \\
\hline Negative & $29(69.0 \%)$ & $12(75.0 \%)$ & \\
\hline Histologic differentiation & & & 0.979 \\
\hline Well & $8(19.0 \%)$ & $3(18.8 \%)$ & \\
\hline Moderate/poor & $34(81.0 \%)$ & $13(81.3 \%)$ & \\
\hline Pathologic T stage & & & 0.501 \\
\hline $\mathrm{T} 1 / \mathrm{T} 2$ & $22(53.7 \%)$ & $7(43.8 \%)$ & \\
\hline $\mathrm{T} 3 / \mathrm{T} 4$ & $19(46.3 \%)$ & $9(56.3 \%)$ & \\
\hline Pathologic N stage & & & 0.470 \\
\hline Positive & $1(02.4 \%)$ & $1(06.3 \%)$ & \\
\hline Negative & $41(97.6 \%)$ & 15 (93.7\%) & \\
\hline No. of patients & 19 & 39 & \\
\hline Lymphangiosis carcinomatosa & & & 0.035 \\
\hline Positive & $9(47.4 \%)$ & $8(20.5 \%)$ & \\
\hline Negative & 10 (52.6\%) & 31 (79.5\%) & \\
\hline
\end{tabular}


Table 5 Correlation of TILs in the tumour central area (TCA) with clinicopathological characteristics in HCC

\begin{tabular}{|c|c|c|c|}
\hline Variable & $\mathrm{TIL}^{+} / \mathrm{TCA}$ & $\mathrm{TIL}^{-} / \mathrm{TCA}$ & $p$ value \\
\hline No. of patients & 20 & 38 & \\
\hline Patient age, years & & & 0.476 \\
\hline$\leq 60$ & $6(30.0 \%)$ & $15(39.1 \%)$ & \\
\hline$>60$ & $14(70.0 \%)$ & $23(60.9 \%)$ & \\
\hline Gender & & & 0.732 \\
\hline Female & $15(75.0 \%)$ & $30(78.9 \%)$ & \\
\hline Male & $5(25.0 \%)$ & $8(21.1 \%)$ & \\
\hline Local tumour recurrence & & & 0.933 \\
\hline Positive & $6(30.0 \%)$ & $11(28.9 \%)$ & \\
\hline Negative & $14(70.0 \%)$ & $27(71.1 \%)$ & \\
\hline Overall tumour recurrence & & & 0.546 \\
\hline Positive & $9(45.0 \%)$ & $14(36.8 \%)$ & \\
\hline Negative & $11(55.0 \%)$ & $24(63.2 \%)$ & \\
\hline Metastases & & & 0.884 \\
\hline Positive & $4(20.0 \%)$ & $7(18.4 \%)$ & \\
\hline Negative & $16(80.0 \%)$ & $31(81.6 \%)$ & \\
\hline Multiple tumour nodules & & & 0.100 \\
\hline Positive & $18(90.0 \%)$ & $27(71.1 \%)$ & \\
\hline Negative & $2(10.0 \%)$ & $11(28.9 \%)$ & \\
\hline Tumour size (mm) & & & 0.206 \\
\hline$\leq 50$ & $2(10.0 \%)$ & $9(23.7 \%)$ & \\
\hline$>50$ & $18(90.0 \%)$ & $29(76.3 \%)$ & \\
\hline R status & & & 0.148 \\
\hline Positive & $15(75.0 \%)$ & $34(89.5 \%)$ & \\
\hline Negative & $5(25.0 \%)$ & $4(10.5 \%)$ & \\
\hline Angioinvasion & & & 0.717 \\
\hline Positive & $11(55.0 \%)$ & 19 (50.0\%) & \\
\hline Negative & $9(45.0 \%)$ & $19(50.0 \%)$ & \\
\hline Lymphangiosis carcinomatosa & & & 0.057 \\
\hline Positive & $9(45.0 \%)$ & $30(78.9 \%)$ & \\
\hline Negative & $11(45.0 \%)$ & $8(21.1 \%)$ & \\
\hline Histologic differentiation & & & 0.576 \\
\hline Well & $3(15.0 \%)$ & $8(21.1 \%)$ & \\
\hline Moderate/poor & $17(85.0 \%)$ & $30(78.9 \%)$ & \\
\hline Pathologic T stage & & & 0.708 \\
\hline $\mathrm{T} 1 / \mathrm{T} 2$ & $9(47.4 \%)$ & $20(52.6 \%)$ & \\
\hline $\mathrm{T} 3 / \mathrm{T} 4$ & $10(52.6 \%)$ & $18(47.4 \%)$ & \\
\hline Pathologic N stage & & & 0.296 \\
\hline Positive & $0(00.0 \%)$ & $2(5.3 \%)$ & \\
\hline Negative & $20(100.0 \%)$ & $36(94.7 \%)$ & \\
\hline $\mathrm{CD} 8^{+}$TAMs/TCA & & & 0.008 \\
\hline Positive & $20(100.0 \%)$ & $11(28.9 \%)$ & \\
\hline Negative & $0(00.0 \%)$ & $27(71.1 \%)$ & \\
\hline
\end{tabular}

specimens of patients with de novo HCC in noncirrhosis after oncologic resection. In addition, their association with patient' clinicopathologic characteristics and survival was analysed. The major discoveries were (1) $\mathrm{CD}^{+} 8^{+}$TAMs were associated with decreased rates of recurrent and multifocal disease; (2) conversely, M2polarized TAMs correlated with lymphangiosis carcinomatosa and multifocal HCC; (3) TILs and infiltrating $\mathrm{CD}^{+}{ }^{+}$TAMs were strongly associated in HCC; and (4) had a potent influence on recurrence-free survival.

In this study, we demonstrated that $\mathrm{CD}^{+} 8^{+} \mathrm{TAMs}$ and M2-polarized TAMs correlate with established clinicopathologic features of advanced de novo HCC in non-cirrhosis. Of note, 29/58 (50\%) of the HCC patients in our study had T3/T4 tumours and 47/58 (81\%) tumours exhibited moderate/poor histologic differentiation. These results are in accordance with previously published results in $\mathrm{HCC}$ and other hepatobiliary tumours, which report on a negative impact of M2 polarization state of infiltrating TAMs on patient survival and outcome $[18,19]$. However, when considering $\mathrm{CD}^{+}{ }^{+}$TAMs, most published results demonstrate a negative value in regard to patient outcome [20]. Here, $\mathrm{CD}^{+} 8^{+}$TAMs were associated with significantly prolonged survival. A possible scenario for our results could be that TAMs comprise a diverse and heterogeneous cell population which can express markers typical not only for M1 or M2 polarization states. Their functionality strongly depends on the signals deployed by the tumour microenvironment, i.e. TAMs re-education and reprogramming as classical tumour escape mechanisms. In line with this, Li et al. demonstrated CD68 ${ }^{+}$TAMs to be also CD204 ${ }^{+}$or $\mathrm{CD}_{169}{ }^{+}$cells. The tissue frequency of CD204 ${ }^{+}$TAMs associated with poor outcome. Conversely, CD169 ${ }^{+}$TAMs were associated with better survival [19]. Insofar, additional research is needed to investigate the mechanistic interplay between diverse TAMs subpopulations and the tumour microenvironment.

The predominant immune cell population in the tumour vicinity consists mainly of TILs. Accumulating scientific data demonstrates that the type, density and localization of host immunologic tumour infiltration influence its malignant behaviour and could provide clinically informative prognostic biomarkers [21-23]. Furthermore, this immunologic reaction could characterize patient outcome to a greater extent than the diagnostics for the staging of cancer, which are currently applied by conventional histopathology [24]. Consequently, TILs were identified as a reliable immunologic tool in the tumour microenvironment that could be used in clinical trials and translational research. Insofar, here we focused on the prognostic capacity of TILs in tumour specimens of HCC. Our findings indicate that the presence of TILs significantly influence survival of HCC patients after curative surgery. Of note, in our work, intratumoural prevalence of TILs in liver cancer was 

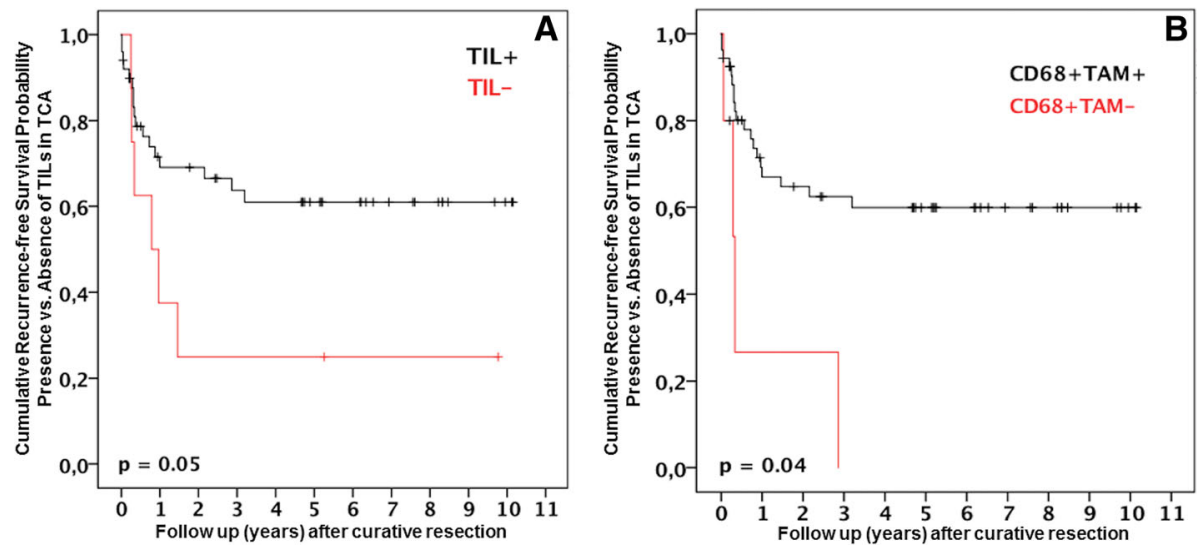

Fig. 2 a Recurrence-free survival for TILs in the TCA. TIL ${ }^{-}$refers to the $\mathrm{TIL}^{-}$group. TIL+ refers to the $\mathrm{TIL}^{+}$group. $\mathbf{b}$ Recurrence-free survival for CD68 ${ }^{+}$TAMs in the TIF. CD68 ${ }^{+}$TAM $^{-}$refers to the CD68 ${ }^{-}$group. $\mathrm{CD}^{+} 8^{+} \mathrm{TAM}^{+}$refers to the $\mathrm{CD}^{+} 8^{+}$group.

correlated with a high frequency of invading TAMs. Thus, it appears possible that infiltrating hepatic monocytes/macrophages and TILs comprise a coherent immunological construct that exerts a significant impact in the process of hepatocarcinogenesis.

In our work, in the setting of oncologic HCC resection, TILs and CD68+ TAMs were associated with better survival rates, which is in line with most published data about TILs' importance in solid cancer that delineates their presence or high tumour density to be associated with improved patient survival [17, 25-27]. Insofar, in this study, we suggest TILs and CD68 ${ }^{+}$TAMs to be reliable cancer biomarkers prognosticating survival and outcome of HCC patients after surgery. However, a possible limitation of the current work is the descriptive nature of our results and the small number of HCC patients with de novo HCC in non-cirrhosis.

\section{Conclusions}

Our study demonstrates that TILs, infiltrating monocytes/ macrophages and their functional polarization state associate with multiple tumour characteristics and patient survival in HCC. However, there is only scarce data about the biology underlying mechanistic involvement of TILs, monocytes/macrophages and their polarization in M1 or M2 subtypes in human tumour progression. Thus, a further examination of underlying functional mechanisms that might help develop novel immunologic checkpoint inhibitor targets for liver cancer is warranted.

\section{Abbreviations}

CCA: Cholangiocarcinoma; HCC: Hepatocellular carcinoma; PDAC: Periductal adenocarcinoma of the pancreas; TAMs: Tumour-associated macrophages; TCA: Tumour central area; TIF : Tumour-infiltrating front

\section{Acknowledgements}

We acknowledge support from the German Research Foundation (DFG) and the Open Access Publication Funds of Charité - Universitätsmedizin Berlin.

\section{Authors' contributions}

GA had significant contributions to the conception of the study; to the generation, analysis, and interpretation of the data; and to preparing the manuscript. KD had significant contributions to the generation and analysis of the data and to preparing the manuscript. KS had significant contributions to the analysis and interpretation of the data and to preparing the manuscript. GA conducted a critical review of the manuscript and resources. DS and JP had significant contributions to preparing the manuscript. MS had significant contributions to the conception of the study, to the analysis and interpretation of the data and to preparing the manuscript. HMH had significant contributions to the conception of the study; to the generation, analysis and interpretation of the data; and to preparing the manuscript. All authors read and approved the final manuscript.

\section{Funding}

This work was made possible by the funding from the Berlin Institute of Health $(\mathrm{BIH})$ to GA. Georgi Atanasov is a participant of the BIH Charité Clinician Scientist Program funded by the Charité - Universitätsmedizin Berlin and the BIH.

Availability of data and materials

The datasets used and/or analysed during the current study are available from the corresponding author on reasonable request.

Ethics approval and consent to participate

Our work was conducted in accordance with the recommendations of the Ethics Committee of the Medical Faculty of the Leipzig University. The committee's reference number is 234-14-14072014. Written informed consent for using the tissue samples was obtained from the patients.

\section{Consent for publication}

N/A

\section{Competing interests}

The authors declare that they have no competing interests.

\section{Author details}

'Department of Visceral-, Transplantation-, Thoracic- and Vascular Surgery, University Hospital Leipzig, Leipzig, Germany. ${ }^{2}$ Department of Surgery, Campus Charité Mitte Campus Virchow Klinikum, Charité -

Universitätsmedizin Berlin, corporate member of Freie Universität Berlin, Humboldt-Universität zu Berlin, and Berlin Institute of Health, Berlin, Germany. ${ }^{3}$ Berlin Institute of Health, Berlin, Germany. ${ }^{4}$ Institute of Pathology, University Hospital Leipzig, Leipzig, Germany. ${ }^{5}$ Department of Surgery, Research Laboratories, University of Leipzig, Leipzig, Germany. 
Received: 26 February 2019 Accepted: 23 May 2019

Published online: 06 June 2019

\section{References}

1. Tacke F. Targeting hepatic macrophages to treat liver diseases. J Hepatol. 2017;66(6):1300-12.

2. Coussens LM, Werb Z. Inflammation and cancer. Nature. 2002:420:860-7.

3. Chen DS, Mellman I. Oncology meets immunology: the cancer-immunity cycle. Immunity. 2013;39:1-10. https://doi.org/10.1016/j.immuni.2013.07.012.

4. Whiteside TL. Targeting adenosine in cancer immunotherapy: a review of recent progress. Expert Rev Anticancer Ther. 2017;17(6):527-35. https://doi. org/10.1080/14737140.2017.1316197. Epub 2017.

5. Najar HM, Ruhl S, Bru-Capdeville AC, Peters JH. Adenosine and its derivatives control human monocyte differentiation into highly accessory cells versus macrophages. J Leukoc Biol. 1990;47:429-39.

6. Xaus J, Valledor AF, Cardo M, Marques L, Beleta J, Palacios JM, et al. Adenosine inhibits macrophage colony-stimulating factor-dependent proliferation of macrophages through the induction of p27kip-1 expression. J Immunol. 1999;163:4140-9.

7. Xaus J, Mirabet M, Lloberas J, Soler C, Lluis C, Franco R, et al. IFN-gamma up-regulates the $\mathrm{A} 2 \mathrm{~B}$ adenosine receptor expression in macrophages: a mechanism of macrophage deactivation. J Immunol. 1999;162:3607-14

8. Semenza GL. Angiogenesis in ischemic and neoplastic disorders. Annu Rev Med. 2003;54:17-28.

9. Chari RS, Helton WS, Marsh RD. Chemotherapy and regional therapy of hepatic colorectal metastases: expert consensus statement by Bartlett et al. Ann Surg Oncol. 2006;13:1293-5.

10. Finotello F, Trajanoski Z. Quantifying tumor-infiltrating immune cells from transcriptomics data. Cancer Immunol Immunother. 2018;67(7):1031-40.

11. Desai A, Sandhu S, Lai JP, Sandhu DS. Hepatocellular carcinoma in noncirrhotic liver: a comprehensive review. World J Hepatol. 2019;11(1):1-18. https://doi.org/10.4254/wjh.v11.i1.1.

12. Atanasov G, Hau HM, Dietel C, Benzing C, Krenzien F, Brandl A, et al. Prognostic significance of TIE2-expressing monocytes in hilar cholangiocarcinoma. J Surg Oncol. 2016;114:91-8.

13. Atanasov G, Pötner C, Aust G, Schierle K, Dietel C, Benzing C, et al. TIE2expressing monocytes and M2-polarized macrophages impact survival and correlate with angiogenesis in adenocarcinoma of the pancreas. Oncotarget. 2018:9(51):29715-26.

14. Atanasov G, Dietel C, Feldbrügge L, Benzing C, Krenzien F, Brandl A, et al. Angiogenic miRNAs, the angiopoietin axis and related TIE2-expressing monocytes affect outcomes in cholangiocarcinoma. Oncotarget. 2018;9(52): 29921-33.

15. Atanasov G, Schierle K, Hau HM, Dietel C, Krenzien F, Brandl A, et al. Prognostic significance of tumor necrosis in hilar cholangiocarcinoma. Ann Surg Oncol. 2017;24(2):518-25.

16. Atanasov G, Dietel C, Feldbrügge L, Benzing C, Krenzien F, Brandl A, et al. Tumor necrosis and infiltrating macrophages predict survival after curative resection for cholangiocarcinoma. Oncolmmunology. 2017;6(8):e1331806.

17. Feng W, Li Y, Shen L, Cai XW, Zhu ZF, Chang JH, et al. Prognostic value of tumor-infiltrating lymphocytes for patients with completely resected stage IIIA(N2) non-small cell lung cancer. Oncotarget. 2016:7(6):7227-40.

18. Minami K, Hiwatashi K, Ueno S, Sakoda M, lino S, Okumura H, Hashiguchi M, Kawasaki Y, Kurahara H, Mataki Y, Maemura K, Shinchi H, Natsugoe S. Prognostic significance of CD68, CD163 and folate receptor- $\beta$ positive macrophages in hepatocellular carcinoma. Exp Ther Med. 2018:15(5):4465-76.

19. Yao RR, Li JH, Zhang R, Chen RX, Wang YH. M2-polarized tumor-associated macrophages facilitated migration and epithelial-mesenchymal transition of HCC cells via the TLR4/STAT3 signaling pathway. World J Surg Oncol. 2018; 16(1):9.

20. Li JQ, Yu XJ, Wang YC, Huang LY, Liu CQ, Zheng L, Fang YJ, Xu J. Distinct patterns and prognostic values of tumor-infiltrating macrophages in hepatocellular carcinoma and gastric cancer. J Transl Med. 2017;15(1):37. https://doi.org/10.1186/s12967-017-1139-2

21. Pagès F, Galon J, Dieu-Nosjean MC, Tartour E, Sautès- Fridman C, Fridman WH. Immune infiltration in human tumors: a prognostic factor that should not be ignored. Oncogene. 2010;29:1093-102.

22. Loi S, MacCallum P. Host antitumor immunity plays a role in the survival of patients with newly diagnosed triple-negative breast cancer. J Clin Oncol. 2014;32:2936-8.
23. Galon J, Mlecnik B, Bindea G, Angell HK, Berger A, Lagorce C, et al. Towards the introduction of the 'immunoscore' in the classification of malignant tumours. J Pathol. 2014;232:199-209.

24. Galon J, Costes A, Sanchez-Cabo F, Kirilovsky A, Mlecnik B, Lagorce-Pagès C, et al. Type, density, and location of immune cells within human colorectal tumors predict clinical outcome. Science. 2006;313:1960-4.

25. Rakaee M, Kilvaer TK, Dalen SM, Richardsen E, Paulsen EE, Hald SM, Al-Saad S, Andersen S, Donnem T, Bremnes RM, Busund LT. Evaluation of tumor-infiltrating lymphocytes using routine H\&E slides predicts patient survival in resected nonsmall cell lung cancer. Hum Pathol. 2018. pii: S0046-8177(18)30185-0.

26. Yao W, He JC, Yang Y, Wang JM, Qian YW, Yang T, Ji L. The prognostic value of tumor-infiltrating lymphocytes in hepatocellular carcinoma: a systematic review and meta-analysis. Sci Rep. 2017;7(1):7525.

27. Sideras K, Biermann K, Verheij J, Takkenberg BR, Mancham S, Hansen BE, Schutz HM, de Man RA, Sprengers D, Buschow SI, Verseput MC, Boor PP, Pan Q, van Gulik TM, Terkivatan T, ljzermans JN, Beuers UH, Sleijfer S, Bruno MJ, Kwekkeboom J. PD-L1, Galectin-9 and CD8 ${ }^{+}$tumor-infiltrating lymphocytes are associated with survival in hepatocellular carcinoma. Oncoimmunology. 2017:6(2):e1273309.

\section{Publisher's Note}

Springer Nature remains neutral with regard to jurisdictional claims in published maps and institutional affiliations.
Ready to submit your research? Choose BMC and benefit from:

- fast, convenient online submission

- thorough peer review by experienced researchers in your field

- rapid publication on acceptance

- support for research data, including large and complex data types

- gold Open Access which fosters wider collaboration and increased citations

- maximum visibility for your research: over $100 \mathrm{M}$ website views per year

At $\mathrm{BMC}$, research is always in progress.

Learn more biomedcentral.com/submissions 